\title{
Developing a Green IS to support the move to eco-effective packaging: A Design Science Research study.
}

\author{
Keith Burton \\ Greenstreets Env Res Ltd \\ keith.burton@greenstreets.ie
}

\author{
Paidi O'Raghallaigh \\ Cork University Business School \\ p.oreilly@ucc.ie
}

\author{
Tadhg Nagle \\ Cork University Business School \\ t.nagle@ucc.ie
}

\begin{abstract}
United Nations Sustainable Development Goal (UN SDG) 12.6 aims to "encourage companies, especially large and transnational companies, to adopt sustainable practices and to integrate sustainability information into their reporting cycle" [43]. Using Design Science Research, GReenstreets ${ }^{l}$ Integrated Packaging Sustainability reporting system ("GRIPS") is an expository artefact built using the BAO design theory for green information systems (Green IS) (c.f. Recker) [34]. The artefact aims to support organizations in overcoming sustainability challenges by providing information to help them make effective decisions around packaging sustainability and to facilitate the move from eco-efficiency to eco-effectiveness practices. This study adds to practice by helping companies to act, measure and monitor the move towards eco-effective packaging. It adds to research by providing an expository artefact based on the design theory for Green IS proposed by Recker [34].
\end{abstract}

\section{Introduction}

In September 2015, the United Nations published its Sustainable Development Goals (UN SDG) for 2030 in which the signatories resolved "to ensure the lasting protection of the planet and its natural resources" [43]. UN SDG 12 concerns itself with "sustainable consumption and production patterns". The Food and Agricultural Organization of the United Nations (FAO) estimates that food waste and food loss account for approximately $8 \%$ of global emissions [15], which if food waste was a country would put its emissions in third place after the US (2nd) and China (1st). In its 2019 report [16], the FAO highlights "the growing awareness and increase in calls for action ... partly based on the fact that losing food implies unnecessary pressure on the environment and the natural resources that have been used to produce it in the first place" and "... essentially means that land and water resources have been wasted,

${ }^{1}$ Greenstreets (a Green IS provider) was set-up to facilitate organizations become eco-effective by pollution created and greenhouse gases (GHGs) emitted to no purpose". UN SDG 12.3 calls for the halving by 2030 of per capita global food waste at the retail and consumer levels and the reduction of food losses along production and supply chains, including post-harvest losses [43].

Packaging plays a critical role in food sustainability by reducing food wastage and the resulting carbon involved in producing wasted food. The Industry Council for Packaging and the Environment report "Table for One" [22] estimates approximately $10 \%$ of energy used for one person's weekly food consumption can be attributed to the packaging. A model developed by Packforsk (see Figure 1) compares the environmental consequences of underestimating and overestimating the amount of packaging required for a product. The model shows that "growth in environmental impact that results from overpackaging is linear. However, the growth in environmental impact that results from under-packaging is exponential ... Over-packaging by $10 \%$ means that $10 \%$ of the resources needed to produce and transport the packaging are unnecessary and therefore wasted. Under-packaging may result in packaging failure, which usually leads to $100 \%$ waste of the resources used to produce and distribute both the product and its packaging" [45].

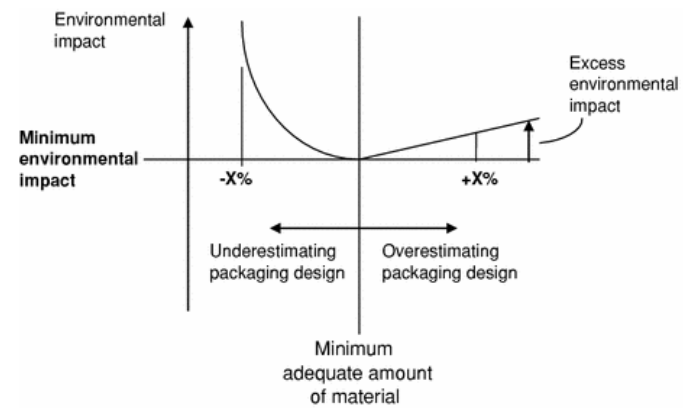

Figure 1 Packforsk Model - impacts of over and under packaging [45]

managing their packaging compliance and sustainability reporting. 
However, packaging is viewed as an unsustainable product with most plastics derived from fossil fuels whose extraction and use cause environmental impacts including increased carbon emissions from production. Geyer et al [18] estimate that approximately 146 megatonnes (MT), or approximately $42 \%$ of primary plastic production in 2015, entered use as packaging with nearly all of this plastic packaging ending up as waste i.e. it is single use and used within the year. In 2017, The Ellen Macarthur Foundation estimated that plastic production is responsible for approximately $1 \%$ of global emissions and $6 \%$ of oil use (plastic packaging accounts for approx. $0.4 \%$ of emissions) and will rise to $15 \%$ of emissions and $20 \%$ of oil use by 2050 [13].

An empirical study by Gholami et al [19] suggests that "coercive pressures influence the attitude of companies adoption of Green IS". Coercive pressures include regulation and pressure from customers and suppliers. From a regulation perspective, the EU Commission has proposed new legislation that will be transposed into national law in each of the 27 member states (and most likely the UK also). Therefore, organizations will face increased legal obligations to report on the sustainability aspects of their packaging, particularly plastics. From a consumer perspective, the Eurobarometer survey (EU Commission 2017) highlighted that $94 \%$ of respondents felt that products should be designed in a way that facilitates recycling of plastic, There has also been a significant increase in activism with movements such as FridayForFuture's school climate strikes [17]. In line with Chen et al.'s [10] sustainability model, taking an eco-efficiency approach to fulfil legislation and customer trends would mean reducing all packaging/plastic without regard to the impact on the food itself. However, an eco-effective approach takes a more holistic approach and ultimately to achieve a better outcome for all involved.

Sustainability reporting (SR) must be adopted by companies to demonstrate this transition. It is of increasing importance due "to pressures from stakeholders for greater transparency on social and environmental impacts" [40]. As the task of "detailed sustainability reporting is complex and involves gathering and processing of a considerable amount of data, green information systems (Green IS) are seen as suitable to support this task". There are some commercially available Green IS for SR, but "their adoption is low.... as there is a lack of knowledge of how to design these IS" [21]. Greenstreets (a Green IS provider) was set-up to facilitate organizations become more eco-efficient by managing their packaging. Many of its customers are large national and transnational retailers that have large product ranges (of in excess of 50,000 products) and international supply chains (of over 1,000 suppliers). With the primary goal of achieving compliance in a cost-efficient manner, these organizations face significant challenges to gather and analyze data as they deal with multiple variations of regulations that transpose EU directives and other legal frameworks differently across multiple jurisdictions.

The purpose of this paper is to describe a design science research project involving the company's ongoing work in the research and development of an expository instantiation of an artefact based on the design theory of Recker [34] which specifies a class of Green IS 'that allow organizations' to perform environmentally sustainable work practices and make environmentally sustainable decisions". The artefact, GRIPSTM, is being developed for the real-world problem of sustainability reporting on plastics and other forms of packaging. The artefact, to our knowledge, is essentially the first rigorous attempt to test the design theory proposed by Recker [34] and a means for improving the eco-effectiveness of organisations.

The structure of this paper is as follows. The next section focuses on the Research Method and outlines the use of a Design Science Research methodology and the reasons for its applicability. The following section focuses on the Artefact Description and outlines the iterations and the development stages of the GRIPS ${ }^{\mathrm{TM}}$ artefact. Finally, we provide a discussion of our findings and outline the contributions.

\section{Research Method}

In this study, Design Science Research (DSR) is used to develop an IS artefact (GRIPSTM) for the real-world problem of sustainability reporting on plastics and other forms of packaging. DSR's raison d'être is "the development of artefacts that can be applied to the solution of real-world problems or to enhance organisational efficacy" [31]. DSR is the design and investigation of artefacts in context [47]. Whereas "natural sciences and social sciences try to understand reality, DSR attempts to create things that serve human purposes" [32]. The main principle of DSR is therefore to "create knowledge and understanding of a problem through the building and the application of an artefact" [20].

Real world IS problems generally involve a mix of IT systems, data, people and behaviors that all interact with each other. Real world problems are fuzzy [3] and the complex and multivariate nature of the social setting [23] means that traditional empirical methods on their 
own may not be appropriate. In McKay and Marshall [26] the methods of natural science are viewed as problematic and inappropriate in "human" disciplines because human agents can act which affects both the phenomena being studied and the outcomes of the research. Baskerville and Wood Harper [4] state that the observation of social setting places greater demands on the observer because of complexity. Chatterjee [9] concludes that the "intention of bringing DSR into the IS community as a methodology was to solve wicked problems". In this study, DSR is used because sustainability "in all of its manifestations is, by nature, a wicked problem" [46]. Brendel et al suggest that the development and evaluation of "novel GIS artifacts falls under the overarching research paradigm of DSR" [7]. We also consider VomBrocke and Siedel's conjecture that DSR should also consider "the sustainability of a design artefact, that is its direct and indirect effects on the natural environment, (a) in the general principles of design science, (b) in the rigorous application of practice rules, and (c) all stages of the design research process"'[8]

\section{Artefact Description}

Using a Practitioner Design Science Research ([28, 39]) approach the GRIPS artefact was developed within Greenstreets over four iterations (between May 2017 and August 2019) to provide a single source of the truth (SSOT) to facilitate organizations in making sense of food packaging from an eco-effectiveness (rather than the more traditional eco-efficiency) perspective. It was developed by implementing the Green IS design theory principles proposed by Recker [34] (See Figure 2) which are drawn from the kernel theories of the Belief Action Outcome Framework [27] and Affordance Theory [38]. Recker [34] specifies a class of Green IS 'that allow organizations' to perform environmentally sustainable work practices and make environmentally sustainable decisions". Green IS has been defined as "the design and implementation of IS that contribute to sustainable business processes" [6] and by Chen et al. as "the use of information systems to enhance sustainability across the economy" [10]

Using the constructs in Recker [34], the artefact was developed for the Belief Action Outcome at the Macro level (Figure 2). The material property of Data Collection is achieved with a redesigned data collection template. This is an Excel based collection spreadsheet that is sent to product suppliers to provide information on the packaging supplied on their products. In Iteration 1, a data model for plastic reporting (Figure 3) was developed. This is also the foundation for the Data Analytics material property. Data from suppliers' templates are imported into the GRIPSTM system for analysis. Changes to the GRIPSTM user interface were also necessary to enable the user to update data on the system directly. For the Data Presentation property, new dashboards (Figure 4) were designed using the learnings from Iteration 2.

Arnott and Pervan [2] identified seven types of Decision Support Systems (DSS) which include Data warehousing (DW). DWs are "an integrated repository for internal and external data-intelligence critical to understanding and evaluating the business" and with "the addition of models, analytic tools, and user interfaces, they have the potential to provide actionable information resources-business intelligence that supports effective problem and opportunity identification, critical decision-making, and strategy formulation, implementation, and evaluation" [24]. GRIPS $^{\text {TM }}$ provides a DW and dashboard tools that can therefore be considered a DSS and it affords "live decision review". The dashboards and access to the DW allow for Action Formation. The dashboards support export to Excel, PDF or image file which affords the user the possibility for knowledge sharing.

\subsection{Iteration 1}

In this iteration, the artefact created was a data model to support plastics reporting. The data model consists of the transactional database schema for managing packaging data and a data warehouse schema for reporting. The model was designed using agile data design (ADD) tools, the Data Value Map [29] and the Data Model Canvas [36]. The model was evaluated using test data against the criteria of the UK Plastics Pact [48] and Repak Plastic Pilot [35]. The data model was demonstrated to several parties and internal employees in January 2019. The desired business impact was to develop a data model that supports the data requirements of the plastics reporting frameworks. The key learning from this iteration was that while the data model is a key component of being able to generate value from the data for our customers, there was a disconnect as to how this might happen.

\subsection{Iteration 2}

The second iteration was driven by feedback received from Iteration 1 and from further research into the problem that sought to ensure the company was solving the "right problem". Using the SoWoHo framework and ADD tools [30], we revisited the problem to explore the vision for the project further. Dashboards enable staff at all levels to view all key facts/metrics and start the exploration of the data [37]. According to Eckerson 
[12], dashboards should be "full-fledged business information systems designed to help organisations optimize performance and achieve strategic objectives". One of Eckerson's principles is the MAD (monitor, analyse and drill to detail) framework and defines how a dashboard should section information in layers based on the MAD principles. Considering the requirements of different practitioner audiences, Drechsler [11] hypothesized that "considering these audiences more deliberately and in greater detail during an artefact's design will increase an artefact's actual utility, relevance, and informing power and, in the long term, the practical relevance of the discipline as a whole". This resulted in the development and evaluation of a low-fidelity (lo-fi) dashboard prototype that was demonstrated to a key customer. While the customer

could see the value of the prototype, the advice was to continue to focus on the packaging element of the project as this was where the customer felt the "greatest need".

\subsection{Iteration 3}

The purpose of this iteration was to integrate the key elements from the data model from Iteration 1, and the dashboard learnings from Iteration 2 into the GRIPS ${ }^{\mathrm{TM}}$ system to support Plastic Reporting. Additionally, the research goal of this iteration was to determine how the artefact provides for "belief formation, action formation and outcome assessment for decisions and practices" that "must be supported by information systems in order to belong to the class of Green IS" [34]. The design/build of this phase was significant in terms of build time and resulted in a significantly improved GRIPSTM application. Evaluation was completed through emulations using "real data" from a "real customer", in the form of a submission to Repak of Repak Plastic Pilot (RPP) data, considered the "proof of the pudding" [44]. The purpose of this evaluation was to show that the "artefact is both applicable and useful in practice" [41]. The goals were to demonstrate that the artefact allows the user to generate the RPP data. The artefact was used with the H1-2019 data provided by customer VAL216 (coded for confidentiality). Additionally, during H1-2019, new packaging specification data was collected from the suppliers of VAL216 (using the new data collection template). This data was loaded into the modified GRIPSTM ${ }^{\text {Tystem }}$ and the H1-2019 calculations were performed in GRIPS. Once calculated the Repak Return Form and Repak Plastic Pilot forms were created and exported from GRIPS. The user carried out comparisons / validation checks to ensure the validity of the data. The calculations were submitted to the customer and then to Repak.

\section{Evaluation and Demonstration}

\section{(Iteration 4)}

Artificial ex-ante evaluation was used in the first two iterations, while an exploratory focus group and confirmatory focus group was used in the latter iterations. The purpose of evaluation is to "determine if we have made any progress" [25]. Prat et al. [33] propose a hierarchy of criteria for the evaluation of artefacts (See Figure 5). The artefact evaluated in iteration 1 was the data model for plastics and the Star Schema for the data warehouse for plastics reporting.

In this iteration, the criteria dimensions (E1 in Figure 5) selected for the evaluation consisted firstly of the "Goal" dimension and in particular two of its subcriteria:

- Efficacy - the degree to which the artefact produces its desired effect;

- Validity - the degree to which the artefact works correctly.

The second dimension (E2) evaluated in this iteration was Structure. This was chosen because the artefact is an entity-relationship model and is more "appropriately termed a model" [25]. The Structure dimension is therefore appropriate for this evaluation and the criteria of completeness, simplicity and clarity were used for evaluation purposes [1, 33]. Homomorphism is the correspondence of a model (structure) with another model, or the fidelity of a model to modelled phenomena [33]. Venable et al [44] provide a framework for evaluation strategies and suitable methods for evaluation. For this evaluation, an ex-ante artificial evaluation of the data models was used. The reasons for this were to test the artefact efficacy where the cost and time required were constraints on the project to evaluate the design of the partial prototype (an instantiation of the data model). The method chosen was a computer simulation. The ERDPlus (https://erdplus.com) modelling tool provides a method to export the SQL scripts of the designed model. Using these scripts, an instantiation of the data model ("the prototype") was created and test data was loaded into the instantiation. Based on the test results, the model was determined to be valid i.e. it returns the expected results. Secondly, the model proved to be effective, in that it can produce the required reporting data for plastics and for other materials. In relation to environment criteria, it was also determined that the model can provide positive environmental indirect 
effects in that it improves the monitoring and reporting for plastics which will form the basis of companies making changes. In relation to completeness, the evaluation determined that the model supports the calculations of recycled content. However, how recyclability can be determined automatically by an IS needs further investigation and is outside of scope. In relation to homomorphism and in particular the correspondence with another model, the BOM structure is a popular data modelling construct and the "star schema or dimensional model has been recognized as an effective structure for organizing many data warehouse components" [5]. We argue therefore that there is homomorphism in the design.

Tremblay et al. [42] suggest that focus groups can be used in DSR and that there are two type of groups. Firstly, an Exploratory Focus Group (EFG) used to study the artefact design and propose improvements in the design. The second type is the Confirmatory Focus Group (CFG) to establish utility of the artefact in field use. For evaluation in Iteration 2, two teams (groups), the Green Team for EFG and the Red Team for CFG. The evaluation process used by the Green team was to "iteratively refine the artefact" [42]. Greenstreets staff carried out "formative" evaluations / exploratory design work. This evaluation was built into the design of the prototypes. The Red Team's role was to act as a proxy for the customer; the team was made up of the members of Greenstreets sales team who are the main channels for selling products and services to customers. When the data model concept was presented to them in January 2019/Feb 2019 there was a lack of "shared understanding" and they did not understand what the project was about or what benefits it would bring to customers. The data model did not resonate with them. However, when they were presented with the lo-fi dashboards, they could see the utility in the artefact. They did raise concerns about the existence of similar platforms for energy and water that were more mature and in use by some large customers. They were also concerned about the length of time that it could take to bring this to the market. In March 2019, a demonstration of the dashboard prototype was carried out with an Environmental Health and Safety Manager from a large international retail company. Following the demonstration, an interview of approximately 45 minutes took place in which the following questions were posed:

- Would the system being proposed be needed in the organisation? (Novelty \& Utility)

- What key reporting areas were of value to the organisation? (Utility \& Fit)

- What proposed functionality was of most interest to the organisation? (Utility \& Fit)
The feedback from the interviewee was analysed and summarised using the Prat et al. [33] framework (see Figure 6).

\section{Findings and Discussion}

This study contributes to research by providing an expository instantiation of an artefact based on the Design Theory that specifies a class of Green IS "that allow organizations' to perform environmentally sustainable work practices and make environmentally sustainable decisions" proposed by Recker (2016). In August 2019, the GRIPS ${ }^{\text {TM }}$ artefact was implemented, operationalized and demonstrated to show that it "works in practice" by allowing the user to generate recyclability information for reporting on the reporting initiative set out by the Repak Plastic Pilot [35] in Ireland for three pilot customers. This served "to see how the artefact interacts with organizational elements, i.e. 'real tasks', 'real users'..." [41]; it enabled the customers to identify areas for eco-efficiency e.g. "light weighting" opportunities. It also afforded the opportunity for insights on eco-effectiveness by providing customers with a sensemaking device to analyze the total environmental impacts of food packaging used in their products. A key aspect of this affordance is the ability to calculate the percentage of recycled content and the recyclability of packaging by brand, supplier, and customer. This provides the ability to prioritize areas for action (change packaging) and to monitor the outcome of that action.

The primary artefact is an example of how the primary role of Green IS in sustainability transformations is to create affordances for sensemaking and sustainable practices [38]. Through this DSR study a range of affordances are instantiated and explored: (i) reflective disclosure affordances at the macro level by providing information to allow the "imagination of alternative work practices"[38], (ii) democratization affordances by providing "action possibilities" to "communicate" and "interpret" information in light of environmental action goals (e.g. recycled content should be 30\%)[38], and (iii) live decision review affordances that the use artefact provides for decision support $[2,24]$. From the study, it was found that reflective disclosure affordances were most important for achieving ecoeffectiveness, whereas the latter two are most aligned with eco- efficiency.

In practice, we are using the artefact to work with a large food retailer and two large food companies to help implement and monitor large sustainable transformation processes to assess and find new packaging on over 5,000 products to be recyclable, 
reusable or compostable by 2025 (i.e. a move towards eco-effectiveness of packaging).

A limitation of this study is that it is mostly concerned with the "macro-level" or organisations[34]. Future directions could include the study of Belief Action Outcome [27, 34] at the micro level or the individual level.

Future directions could include the investigation of the applicability of the artefact to assess the ecoeffectiveness of other material streams such as electronics, textiles etc.

\section{References}

[1] Aier, S., and C. Fischer, "Criteria of progress for information systems design theories", Information Systems and e-Business Management 9(1), 2011, pp. 133-172. [2] Arnott, D., and G. Pervan, "Design Science in Decision Support Systems Research: An Assessment using the Hevner, March, Park, and Ram Guidelines", Journal of the Association for Information Systems 13(11), 2012, pp. 923949.

[3] Avison, D., F. Lau, M. Myers, and P.A. Nielsen, “Action Research:To make academic research relevant, researchers should try out their theories with practitioners in real situations and real organizations.", Communications of the ACM 42(1), 1999, pp. 94-97.

[4] Baskerville, R., and A. Wood-Harper, "Diversity in information systems action research methods", European Journal of Information Systems 7(2), 1998, pp. 90-107. [5] Berndt, D.J., A.R. Hevner, and J. Studnicki, "The Catch data warehouse: Support for community health care decisionmaking”, Decision Support Systems 35(3), 2003, pp. 367384.

[6] Boudreau, M.-C., A. Chen, and M. Huber, Green IS: Building Sustainable Business Practices, 2008.

[7] Brendel, A.B., P. Zapadka, and L.M. Kolbe, "Design Science Research in Green IS: Analyzing the past to guide future research", Twenty-Sixth European Conference on Information Systems, (2018).

[8] Vom Brocke, J., and S. Seidel, "Environmental sustainability in design science research: Direct and indirect effects of design artifacts", Lecture Notes in Computer Science (including subseries Lecture Notes in Artificial Intelligence and Lecture Notes in Bioinformatics), Springer, Berlin, Heidelberg (2012), 294-308.

[9] Chatterjee, S., "Writing my next Design Science Research masterpiece: But how do I make a theoretical contribution to DSR?”, Ecis(2015), 2015, pp. Paper 28. [10] Chen, A.J.W., M.C. Boudreau, and R.T. Watson, "Information systems and ecological sustainability", Journal of Systems and Information Technology 10(3), 2008, pp. 186-201.

[11] Drechsler, A., "Designing to inform: Toward conceptualizing practitioner audiences for socio-technical artifacts in design science research in the information systems discipline", Informing Science 18(1), 2015, pp. 3145.
[12] Eckerson, W.W., Performance Dashboards Measuring, Monitoring, and Managing Your Business, John Wiley \& Sons, Ltd, 2011.

[13] Ellen Macarthur Foundation, "The New Plastics Economy: Rethinking the future of plastics", 2017, 22. https://www.ellenmacarthurfoundation.org/assets/downloads/ publications/NPEC-Hybrid_English_22-11-17_Digital.pdf [14] EUCommission, Special Eurobarometer 468: Report Attitudes of European citizens towards the environment, 2017.

[15] FAO, "Food wastage footprint \& Climate Change", 2015. http://www.fao.org/3/a-bb144e.pdf

[16] FAO, The State of Food and Agriculture 2019. Moving forward on food loss and waste reduction, Food and Agriculture Organisation of the United Nations, 2019.

[17] FridaysForFuture, "FridaysForFuture", 2019. https://www.fridaysforfuture.org/

[18] Geyer, R., J.R. Jambeck, and K.L. Law, "Production, use, and fate of all plastics ever made.", Science advances 3(7), 2017, pp. e1700782.

[19] Gholami, R., A.B. Sulaiman, T. Ramayah, and A. Molla, "Senior managers' perception on green information systems (IS) adoption and environmental performance: Results from a field survey", Information and Management 50(7), 2013, pp. 431-438.

[20] Hevner, A.R., S.T. March, and J. Park, "Design Science in Information Research", MIS Quarterly 28(1), 2004, pp. $75-105$.

[21] Hilpert, H., J. Kranz, and M. Schumann, “An Information System Design Theory for Green Information Systems for Sustainability Reporting-Integrating theory with evidence from multiple case studies", Proceedings of the European Conference on Information Systems (ECIS), (2014).

[22] INCPEN, Table for one - The energy cost to feed one person, 2009.

[23] Järvinen, P., "Action research is similar to design science", Quality and Quantity 41(1), 2007, pp. 37-54. [24] March, S.T., and A.R. Hevner, "Integrated Decision Support: A Data Warehousing Perspective", AIS SIGDSS Pre-ICIS Workshop Research Directions on Decision Support., 2003.

[25] March, S.T., and G.F. Smith, "Design and natural science research on information technology", Decision Support Systems 15(4), 1995, pp. 251-266.

[26] McKay, J., and P. Marshall, "The dual imperatives of action research", Information Technology \& People 14(1), 2001, pp. 46-59.

[27] Melville, N.P., "Information Systems Innovation for Enviornmental Sustainability”, MIS Quarterly 34(1), 2010, pp. 1-21.

[28] Nagle, T., and D. Sammon, "The development of a Design Research Canvas for data practitioners", Journal of Decision Systems 25(sup1), 2016, pp. 369-380.

[29] Nagle, T., and D. Sammon, "The Data Value Map: A Framework for developing shared understanding on data initiatives", ECIS 2017 Proceedings(ii), 2017, pp. 14391452.

[30] O'Reilly, P., “Agile Data Design - Rebooting our Thinking Using the SoWoHo Framework", Lecture Notes IMI Data Business, 2018. 
https://imi.learnonline.ie/pluginfile.php/47527/mod_folder/co ntent/0/Paidi - October 2018/IMI Data Workshop -

Innovation Design Thinking Day 1-2 Run 5

Final.pdf?forcedownload $=1$

[31] Peffers, K., T. Tuunanen, and B. Niehaves, "Design science research genres: introduction to the special issue on exemplars and criteria for applicable design science

research", European Journal of Information Systems 27(2),

2018, pp. 129-139.

[32] Peffers, K., T. Tuunanen, M.A. Rothenberger, and S. Chatterjee, "A Design Science Research Methodology for Information Systems Research", Journal of Management Information Systems 24(3), 2008, pp. 45-77.

[33] Prat, N., I. Comyn-Wattiau, J. Akoka, I. Wattiau, and J. Akoka, "Artifact Evaluation in Information Systems DesignScience Research-A Holistic View", Proceedings - Pacific Asia Conference on Information Systems, PACIS, (2014). [34] Recker, J., "Toward a design theory for green information systems", Proceedings of the Annual Hawaii International Conference on System Sciences, IEEE (2016), 4474-4483.

[35] Repak, Plastic Packaging Recycling Strategy 20182030, 2018.

[36] Sammon, D., and T. Nagle, Data Model Canvas, 2016. [37] Schultz, G.J., "Enterprise Performance Management: Strategic Decision Analytics from Deep Data.", The Executive's Journal 20(3), 2004, pp. 14-24.

[38] Seidel, S., J. Recker, and J. vom Brocke, "Sensemaking and Sustainable Practicing: Functional Affordances of Information Systems in Green Transformations", MIS Quarterly 37(4), 2013, pp. 1275-1299.

[39] Sein, Henfridsson, Purao, Rossi, and Lindgren, "Action Design Research”, MIS Quarterly 35(1), 2011, pp. 37.

[40] Siew, R.Y.J.J., "A review of corporate sustainability reporting tools (SRTs)", Journal of Environmental Management 164, 2015, pp. 180-195.

[41] Sonnenberg, C., and J. Vom Brocke, "Evaluation patterns for design science research artefacts",

Communications in Computer and Information Science, (2012), 71-83.

[42] Tremblay, M.C., A.R. Hevner, and D.J. Berndt, "Focus Groups for Artifact Refinement and Evaluation in Design

Research", Communications of the Association for

Information Systems 26(27), 2010, pp. 599-618.

[43] United Nations, Transforming Our World: The 2030

Agenda For Sustainable Development, 2015.

[44] Venable, J.R., J. Pries-Heje, and R. Baskerville, “A Comprehensive Framework for Evaluation in Design Science Research", In 2012, 423-428.

[45] Verghese, K., H. Lewis, and L. Fitzpatrick, Packaging for sustainability, Springer, London, 2012.

[46] Waddock, S., "The Wicked Problems of Global Sustainability Need Wicked (Good) Leaders and Wicked (Good) Collaborative Solutions", Journal of Management for Global Sustainability 1(1), 2013, pp. 91-111.

[47] Wieringa, R., Design Science Methodology for

Information Systems and Software Engineering, Springer

Berlin Heidelberg, 2014.

[48] WRAP, A Roadmap to 2025 - The UK Plastics Pact WRAP UK, 2018. 
Constructs of the Green IS Design Theory, with exemplary potential design instantiations

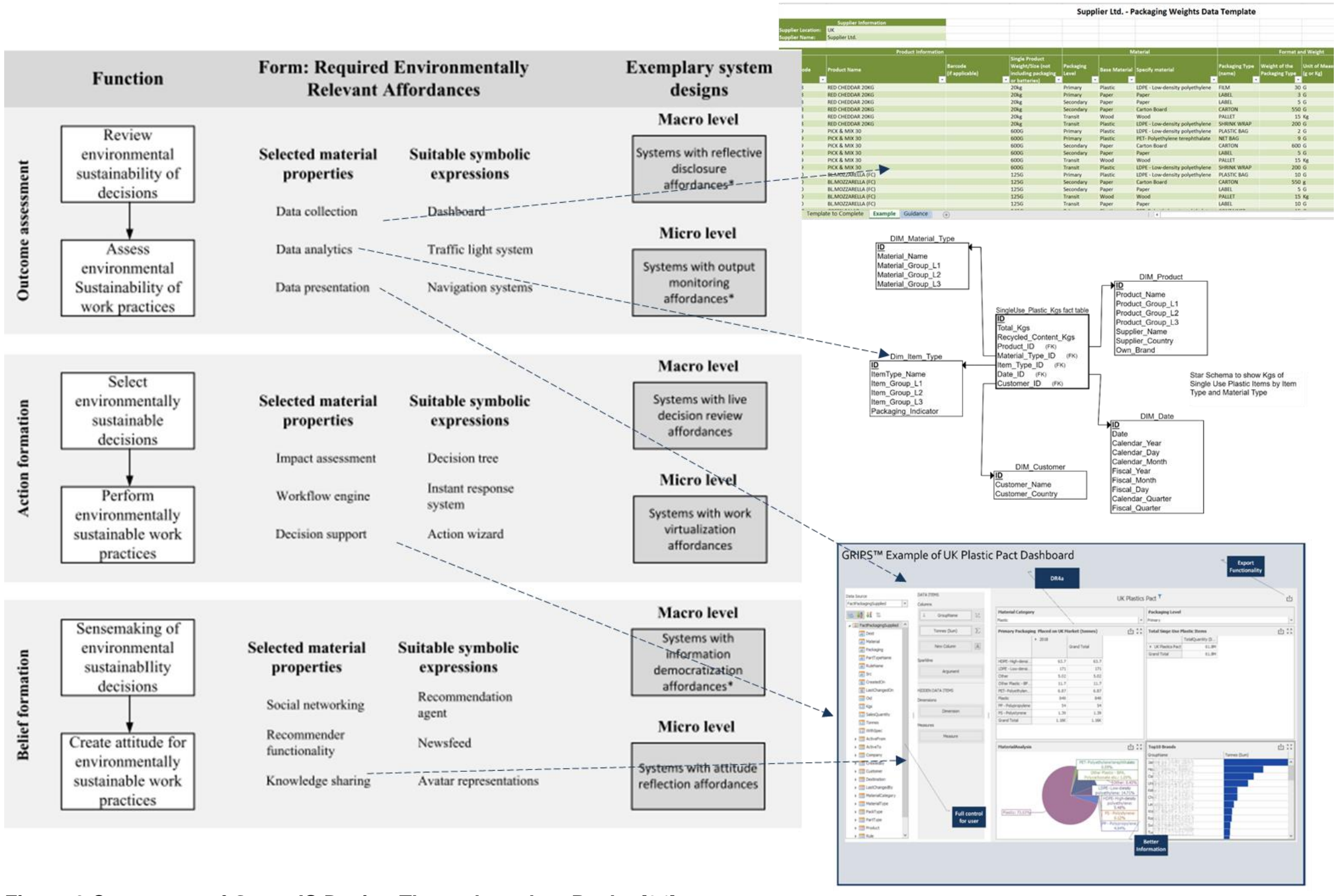

Figure 2 Constructs of Green IS Design Theory based on Recker[34] 


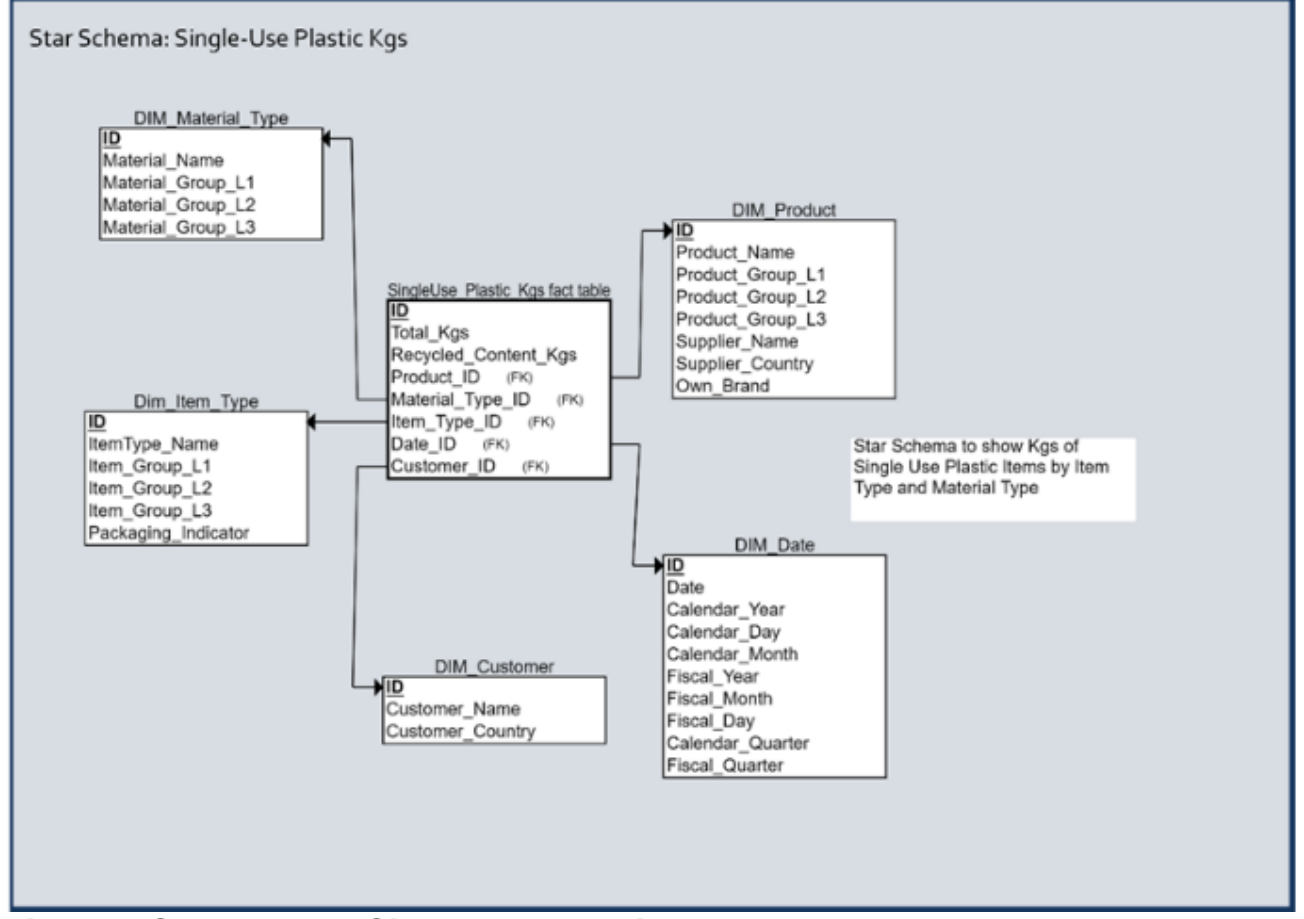

Figure 3 Star schema Single Use Plastics

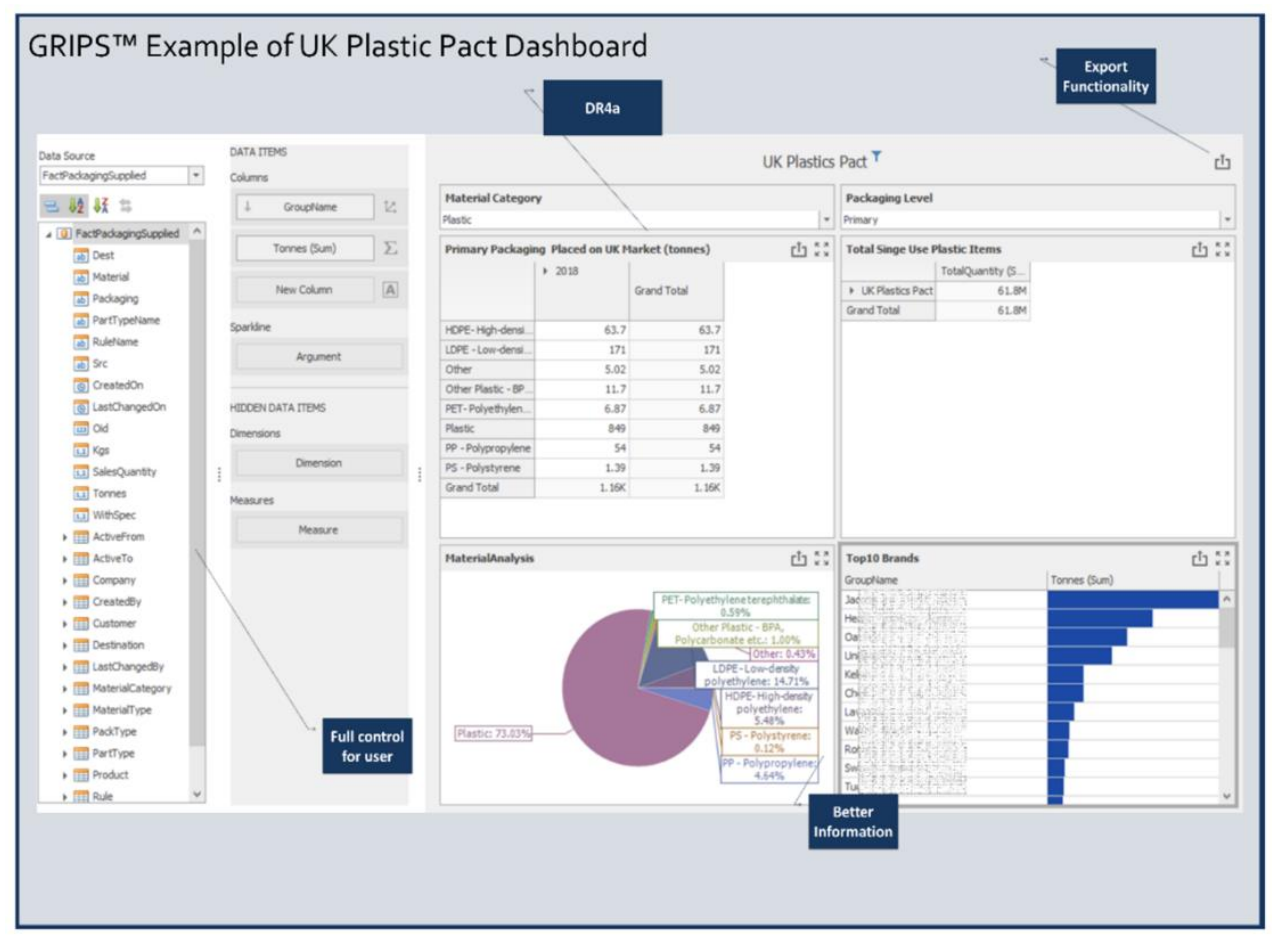

Figure 4 Example of GRIPS dashboard 
Evaluation - Prat et al, 2014

E1 Goal based evaluation

E2 Prat et al, 2014 suggest using structure criteria for the evaluation of models.

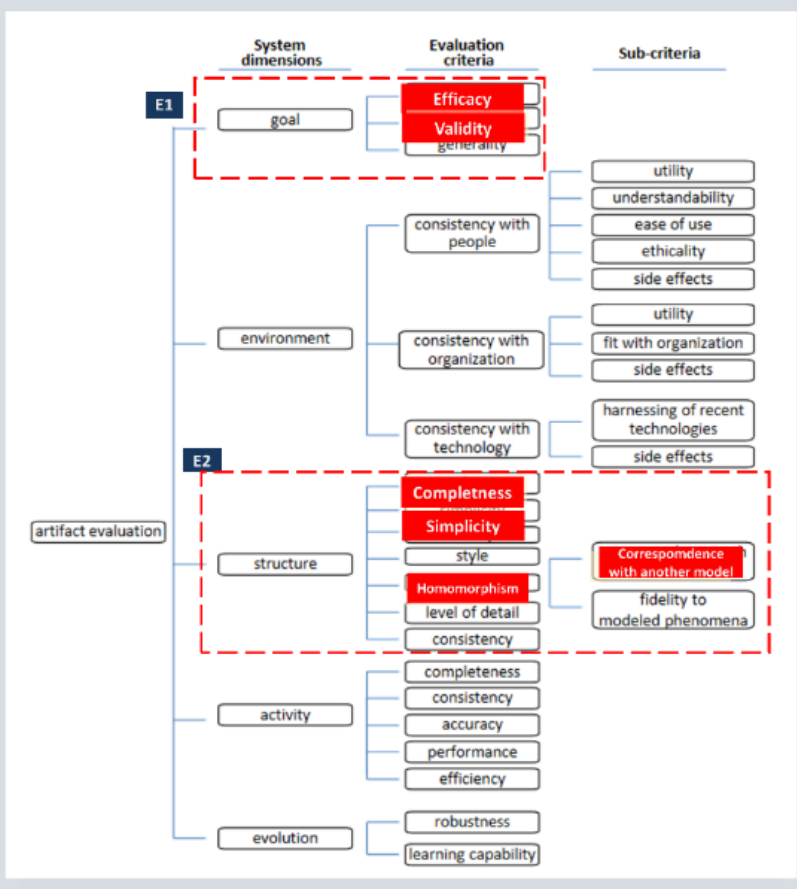

Figure 5 Hierarchy of evaluation criteria

\begin{tabular}{|c|c|c|c|c|c|c|c|}
\hline & \multirow{2}{*}{$\begin{array}{l}\text { System } \\
\text { Dimensions }\end{array}$} & \multicolumn{2}{|c|}{ Evaluation } & \multicolumn{4}{|c|}{ Audience } \\
\hline & & Evaluation Criteria & Sub Criteria & Green Team & Red Team 䊉h & Customer1 \& & Survey \\
\hline \multirow{16}{*}{ 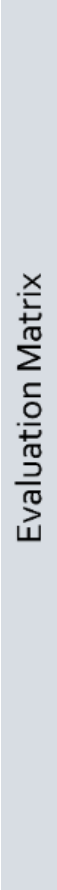 } & \multirow{3}{*}{ 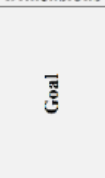 } & Efficacy & & & & $\begin{array}{l}\text { Thinks packaging is } \\
\text { the main goal for his } \\
\text { organisation }\end{array}$ & $\begin{array}{l}\text { Encrey scems to be the main } \\
\text { feature required. Packaging } \\
\text { is fourth. }\end{array}$ \\
\hline & & Validity & & $\begin{array}{l}\text { Believe key metrics } \\
\text { have been identified }\end{array}$ & & $\begin{array}{l}\text { Need to be able to } \\
\text { drill down on costs }\end{array}$ & \\
\hline & & Gencrality & & & $\begin{array}{l}\text { Think it is what } \\
\text { customers are looking }\end{array}$ & & $\begin{array}{l}\text { Appears to meet key } \\
\text { fcatures identificd }\end{array}$ \\
\hline & \multirow{9}{*}{ 䓂 } & $\begin{array}{l}\text { Consistency with } \\
\text { People }\end{array}$ & Utility & & & $\begin{array}{l}\text { Useful. Other systems } \\
\text { have the information } \\
\text { but having it all in one } \\
\text { dashbaord is useful. }\end{array}$ & \\
\hline & & & Understandability & & $\begin{array}{l}\text { Clear benefits for the } \\
\text { customer. }\end{array}$ & & \\
\hline & & & Ease of Use & & & & \\
\hline & & & Ethicality & & & & \\
\hline & & $\begin{array}{l}\text { Consistency with } \\
\text { Organisation }\end{array}$ & $\begin{array}{l}\text { Side Effects } \\
\text { Utilily }\end{array}$ & & & $\begin{array}{l}\text { Packaging and } \\
\text { compliance costs are }\end{array}$ & \\
\hline & & & Fit with Organisation & & & $\begin{array}{l}\text { Gap for packaging } \\
\text { information. So very } \\
\text { timely }\end{array}$ & \\
\hline & & & Side Effects & & & & \\
\hline & & $\begin{array}{l}\text { Consistency with } \\
\text { technology }\end{array}$ & $\begin{array}{l}\text { Hamessing of recent } \\
\text { technologies }\end{array}$ & & & $\begin{array}{l}\text { Needs to be available } \\
\text { on the cloud.. }\end{array}$ & \\
\hline & & & Side Effects & & & concern. & \\
\hline & \multirow{4}{*}{ 莺 } & Completeness & & & & & \\
\hline & & Simplicity & & & & & \\
\hline & & Clarity & & & & & \\
\hline & & Style & & $\begin{array}{l}\text { We need to provide } \\
\text { simple clear } \\
\text { information }\end{array}$ & & $\begin{array}{l}\text { Indicated that this is } \\
\text { very important. Some } \\
\text { recent systems have } \\
\text { failed to achieve } \\
\text { traction because of }\end{array}$ & \\
\hline
\end{tabular}

Figure 6 Summary of evaluation in iteration 2 